\title{
DEBERES Y RESPONSABILIDADES HACIA OTROS
}

\author{
Cristina Sánchez Muñoz \\ Universidad Autónoma de Madrid
}

\begin{abstract}
lo largo de las décadas que llevamos trabajando conjuntamente en el área de Filosofía del Derecho de la UAM, han sido muchos los temas tratados, desde la Teoría de la Justicia, hasta la Teoría del Derecho, desde la Filosofía Política hasta la Historia de la Filosofía Jurídica. Francisco LAPORTA y Liborio HIERRO nos han proporcionado muy valiosas reflexiones en muchos de estos terrenos, que han quedado ya consolidados como hitos en la Filosofía del Derecho de nuestro país. En ocasiones, ese trabajo conjunto ha ido ensamblando piezas que de otra manera hubiesen quedado aisladas y, sin duda, menos enriquecidas intelectualmente. El trabajo que presento en estas páginas pretende, en ese sentido, ensamblar alguna de las piezas menos conocidas de Francisco LAPORTA (pero no por ello menores) encontrando las líneas de continuidad entre ellas.
\end{abstract}

Esas piezas que aglutino responden a momentos distintos de su producción intelectual, pero en ellas podemos observar en realidad, como trataré hacer ver, una preocupación fundamental acerca de nuestros deberes y responsabilidades hacia otros. El primer texto es del año 1986 y lo encontramos en ese número tan relevante y seminal de la revista Doxa, dedicado a los deberes positivos generales, y lleva como título «Algunos problemas de los deberes positivos generales (Observaciones a un artículo de Ernesto Garzón Valdés». La segunda pieza es de 1992, «Los vecinos de Kitty Genovese: la responsabilidad moral de la solidaridad», donde aborda el conocido caso acaecido en Nueva York en $1964^{1}$. La última, muy reciente, es una reflexión sobre los deberes morales que brotan del acontecimiento del Holocausto, y lleva por título «Auschwitz y la justicia» ${ }^{2}$. Nos encontramos por tanto, como pueden ver, con una preocupación por lo que hacemos (y no hacemos) frente a los otros, por nuestros

1 Publicado primero en el libro colectivo En el Umbral del Tercer Milenio, Exposición Universal de Sevilla, 1992, y posteriormente en la revista Tiempo de Paz, núm. 88, primavera 2008. Aquí haré referencia a esta última publicación.

2 Publicado en A. Gómez Ramos y C. SÁnchez Muñoz (eds.) Confrontando el mal. Ensayos sobre violencia, memoria y democracia, Madrid, Plaza y Valdés, 2017. La preocupación de LAPORTA por los problemas derivados del Holocausto viene plasmándose en su docencia desde comienzos del año 2000. Desde ese momento, Francisco LAPORTA, Evaristo PRIETO y yo misma, venimos impartiendo conjuntamente, bajo distintas fórmulas académicas, una asignatura que lleva por título «El Holocausto: Cuestiones éticas, jurídicas y políticas». Primero fue un curso de doctorado, posteriormente una asignatura de las llamadas «Oferta específica», y en los últimos años es una «Asignatura Transversal». Ha sido un largo y satisfactorio recorrido, en donde hemos podido poner en común cuestiones que nos preocupaban a los tres, como la responsabilidad colectiva, las políticas de la memoria o la relación entre comunidad popular y legislación. Han sido muchas las preguntas 
deberes y responsabilidades, tanto en contextos democráticos (como sería en el caso de Genovese) así como en contextos de violencia totalitaria (la Alemania del Tercer Reich). Podríamos añadir, incluso, que hay una secuencialidad y unas escalas entre estas tres piezas: se parte de supuestos de escala «menor», o si se prefiere, face to face (el caso de la responsabilidad del que salva la vida de un menor que se está ahogando), a una escala global y transnacional (la responsabilidad frente al hambre o la pobreza). $\mathrm{Y}$ es en el tercer texto, relativo a Auschwitz, donde se plantea una recolocación de los problemas planteados con la responsabilidad y nuestras acciones y omisiones, en un contexto concreto, pero que tiene la virtualidad de apelar a «la humanidad en su conjunto en el cuerpo del pueblo judío», como dijese Hannah ARENDT a propósito del juicio a Adolf Eichmann ${ }^{3}$. Podríamos decir que el texto sobre Auschwitz nos permite pensar en el Holocausto como un «intensificador» de las cuestiones previas, esto es, nos pone frente a dilemas éticos en los que ya cualquier acción u omisión pueden adquirir el calificativo de supererogatorios dado el contexto en el que tienen lugar, y de otro lado, la cuestión de la responsabilidad colectiva aparece, como veremos, y como se ha encargado de recordar una ya larga bibliografía al respecto, como telón de fondo ineludible.

\section{ACCIONES, OMISIONES Y RESPONSABILIDADES}

Uno de los problemas que le plantea a LAPORTA la formulación de los deberes positivos generales (DPG) por parte de GARZÓN (y de SINGER) es la vinculación que establecen entre responsabilidad moral y responsabilidad causal, donde la omisión es causa de la responsabilidad moral. Por consiguiente, en los DPG, la omisión sería el elemento central para atribuir responsabilidades: «se adscribe esa responsabilidad moral a ciertos individuos o grupos de individuos porque causan con sus omisiones el estado de cosas que se pretende evitar» (LAPORTA, 1986: 56). Sin embargo, como señala LAPORTA, en los casos de interacción face to face, se podrían solventar los complejos problemas de determinar el valor de verdad de un condicional contrafáctico, pero no ocurre lo mismo cuando nos encontramos con supuestos en donde nos encontramos con estados de cosas masivos (el hambre, la pobreza...). En estos casos, el juego de interacciones entre acciones y omisiones se vuelve extremadamente complejo. Lo que echa en falta LAPORTA en la argumentación es, en cierta manera, lo que se ha dado en llamar responsabilidad vicaria (FEINBERG, 1968), esto es, un tipo de responsabilidad en donde el nexo causal es muy débil o está ausente. El que no haya un nexo causal claramente determinado, no significa que no podamos atribuir responsabilidad moral. En el caso de las omisiones en contextos donde se entrecruzan complejas cadenas de acciones (y omisiones), nos encontramos con serias dificultades para demostrar la causación (¿cuántas omisiones son necesarias?, ¿supone un sistema agregativo de omisiones individuales?), dificultades derivadas, entre otras cuestiones, precisamente de la atribución individual y causal de la responsabilidad.

que nos hemos formulado y, me temo, que pocas las respuestas. Algunas de ellas las encontrarán enunciadas en estos textos que estoy comentando.

${ }^{3}$ H. ARENDT, Eichmann en Jerusalén. Un estudio sobre la banalidad del mal, Barcelona, Lumen, 1999, 17. 
Para LAPORTA, es necesario pensar en términos de acciones colectivas y omisiones colectivas para poder atribuir una responsabilidad colectiva, distinta de «las responsabilidades individuales por las omisiones específicas de los integrantes del colectivo» (LAPORTA, 1986: 61).

Pero si la responsabilidad colectiva no es la suma agregativa de las acciones individuales, entonces los problemas que brotan no son menos arduos, centrados fundamentalmente en la definición de grupo y en la intencionalidad del mismo. LAPORTA no utiliza la sin duda escurridiza noción de grupo, sino la de acciones u omisiones coordinadas: «una omisión colectiva se produce en el supuesto de un conjunto determinado de omitentes, cada uno de los cuales realiza una determinada omisión coordinada con las omisiones de los demás. La omisión resultante es un estado de cosas distinto del que se produce con cada una de las omisiones individuales» (LAPORTA, 1986: 61). Sin embargo, si tomamos ahora el caso de Kitty Genovese, en la omisión de los treinta y ocho vecinos que escucharon los gritos de auxilio de la víctima, no podemos mantener que hubiese una omisión concertada o cooperativa ${ }^{4}$. Tampoco había una relación entre los vecinos, ni la solidaridad de grupo que algunos autores reclaman para poder hablar precisamente de la responsabilidad colectiva atribuida a un grupo (FEINBERG, 1968). Quizás la interpretación de Virginia HeLD a propósito de la responsabilidad de grupos, es la que mejor explica la responsabilidad en el caso Genovese. Para HeLD, tendríamos lo que denomina una «aleatoria colección de individuos», conectados o relacionados precisamente en el proceso de producir un daño juntos, en este caso por la omisión colectiva (HELD, 1991). En palabras de GARZÓN VALDÉS, se habría producido una «unanimidad ineficaz», que no tendría por qué ser intencional (GARZÓN, 2011a). Más bien, lo que se habría dado es una dejación individual del deber de socorro, con un resultado colectivo.

En el caso Genovese, sin embargo, podemos decir que esa unanimidad en la omisión se encuentra limitada a un espacio y un momento temporal concreto, es decir, que el nexo causal es más fácil de determinar o rastrear. Sin embargo ¿Qué ocurre en aquellos casos en los que el nexo causal resulta mucho más complejo de determinar? Esto es, en las omisiones colectivas vicarias, donde no solo hay omisiones a gran escala, producidas de una manera masiva por grandes grupos de población, sino que además estas se suelen producir dentro de marcos políticos, sociales o ideológicos determinados. Sin duda, estos serían los casos de los que podríamos denominar «los vecinos globales de Kitty Genovese». Si ampliamos la escala globalmente, tendríamos los ejemplos del hambre en el mundo, la pobreza o situaciones similares. Si nos centramos a una escala no transnacional, sino nacional, tendríamos entonces la responsabilidad colectiva tanto en el caso del Holocausto, como el de otros genocidios. En ambos casos, podemos

${ }^{4}$ En 1964, en el barrio de Queens, Nueva York, la joven Genovese fue asaltada y apuñalada. Durante los cerca de treinta minutos que duraron los hechos, sus gritos fueron oídos por los vecinos del barrio, ninguno de los cuales hizo nada por evitarlo. Desde la sicología social, el caso ha representado lo que se ha llamado el «efecto espectador», esto es, cuando la concurrencia de la presencia de otros desactiva la iniciativa individual y fomenta la abstención. ¿Hasta qué punto las expectativas que podemos tener respecto a que otros hagan algo en nuestras mismas circunstancias exime o reduce nuestra responsabilidad? GARZÓN VALDÉS introduce aquí criterios de razonabilidad en dichas expectativas para graduar la responsabilidad individual. Qué consideramos «expectativas razonables» estaría modulado por la situación concreta, el momento social y político o el momento histórico (GARZÓN, 2011a: 168). 
afirmar junto con LAPORTA: «Estamos inmersos de forma inevitable en el gran río de la causalidad colectiva. No podemos volverle la espalda» (2008: 8).

Respecto al primer supuesto - omisiones masivas a escala transnacional- encontramos entre otras, la idea de responsabilidad por las injusticias estructurales desarrollada por la filósofa Iris Marion Young, desarrollada en su obra póstuma Responsibility for Justice. En ella, la autora plantea precisamente, «que todos los agentes que contribuyen con sus acciones a los procesos estructurales que producen injusticias, tienen responsabilidades para poner remedio a esas injusticias» (YOUNG, 2011). El resultado es un panorama de acciones que se entrecruzan, y en el que YOUNG apuesta por afirmar que: «Nuestra responsabilidad deriva de nuestra pertenencia común a un sistema de procesos interdependientes de cooperación y competición, a través de los cuales intentamos obtener beneficios y hacer realidad nuestros proyectos. Como parte de esos procesos, tenemos responsabilidades, incluso aunque no haya una cadena causal directa que nos permita seguir el rastro de un resultado que pueda hacer que nos lamentemos por nuestras acciones» (YOUNG, 2011) ${ }^{5}$. La injusticia estructural se produce entonces sin una intencionalidad causal, como resultado de acciones u omisiones colectivas que se encuadran dentro de procesos estructurales. Evidentemente, uno de los problemas que surgen de esta afirmación es el de la asimetría: los sujetos que realizan acciones interconectadas en un mundo globalizado no se encuentran en posiciones simétricas, sino que esas acciones se insertan en estructuras sociales que potencian la vulnerabilidad de unos a costa de la satisfacción y el resguardo de otros. Por ello, Young señala que aquellos que están situados en una posición material e institucionalmente más propicia para tener influencia en las condiciones de vulnerabilidad, tienen un mayor número de obligaciones ${ }^{6}$.

\section{DEBERES Y RESPONSABILIDADES A PARTIR DE AUSCHWITZ}

El segundo supuesto que hemos señalado antes —omisiones masivas a escala nacional, producidas dentro de marcos políticos e ideológicos determinados- nos conduciría al examen de la responsabilidad colectiva en el Holocausto. ¿Podríamos decir entonces que el Holocausto fue - salvando las necesarias distancias - un ejemplo del caso Genovese a gran escala? Y si no es así, ¿qué elementos le faltan? De nuevo, ¿qué es lo que hace o conforma el «grupo»? No podemos decir aquí, a diferencia del caso Genovese que estamos ante un grupo aleatorio. Por el contrario, en el contexto de la Alemania del Tercer Reich sí que serían relevantes el interés o la solidaridad compartida en el grupo, de la que hablaba FEINBERG, sostenida en este caso por la ideología antisemita. Estaríamos ante unas creencias compartidas y una estructura social y política también compartidas, que nos permitiría hablar de grupo, aun cuando dentro de ese grupo — la población alemana— también debiéramos distinguir distintos tipos de conductas.

5 Uno de los ejemplos más utilizados por Young es el de la producción textil a bajo coste en Asia o Centroamérica, donde el beneficio obtenido por los consumidores de los países desarrollados resulta a cambio de la explotación laboral de otros.

${ }^{6}$ Desarrollo con más detalle la propuesta de Young en «Responsabilidades globales e injusticias estructurales. Una lectura de Iris Marion YounG», Enrahonar. Quaderns de Filosofia, núm. 51, 2013. 
La bibliografía de las últimas décadas sobre el Holocausto y sobre los genocidios en general, ha puesto de manifiesto la relevancia de los bystanders (espectadores externos) en la consecución de los crímenes, en ocasiones menos pasivos de lo que cabría suponer, y partícipes en lo que Aurelio ARTETA ha denominado «el mal complaciente» (ARTETA, 2010: 67 y ss.). Perpetradores, víctimas y bystanders compondrían la escena de los genocidios, donde, en el caso de Alemania, los «alemanes corrientes» jugaron un papel decisivo al apoyar — con acciones y omisiones- las políticas de exterminio ${ }^{7}$. La dificultad radica en la distribución de esa responsabilidad colectiva. De acuerdo de nuevo con FEINBERG, cuando tratamos esta cuestión tendríamos que distinguir aquellos casos en los que todos los miembros de ese colectivo o grupo comparten la misma falta, y aquellos otros en los que todos los miembros del colectivo contribuyen al resultado, pero con diferentes niveles (FEINBERG, 1968). El primer supuesto correspondería realmente al caso Genovese, mientras que el segundo sí que reflejaría en mi opinión la responsabilidad colectiva de los «alemanes corrientes», donde tendríamos que diferenciar distintas conductas de aceptación del antisemitismo, desde aquellas entusiastas hasta otras más instrumentales para otros fines. Por ello, dentro del grupo o colectivo, hay que analizar también las conductas individuales, y adscribir no solo responsabilidades individuales y colectivas, sino también la culpa individual. Pero es esa «colectivización de la inmoralidad», en este caso, como señala LAPORTA, lo que hace posible hablar de una responsabilidad colectiva (LAPORTA, 2016).

No obstante, tenemos que incidir en la disociación entre responsabilidad colectiva y culpabilidad colectiva, algo que LAPORTA subraya, y que encontramos en autores como Karl JASPERS o Hannah ARENDT, al tratar la cuestión de la supuesta «culpabilidad colectiva» de Alemania tras la guerra. La culpa - lo mismo que la inocencia, mantienen estos autores - es siempre individual. La culpa, en este sentido, tiene una fuerte orientación solipsista (el individuo consigo mismo). No hay culpas vicarias ni colectivas, pero sí responsabilidades vicarias y colectivas (ARENDT, 2007). JASPERS señala, además, que el reconocimiento de esa responsabilidad colectiva es el primer paso para poder construir un nuevo futuro colectivo tras la violencia, y el punto de partida para asumir esa responsabilidad es «el restablecimiento de la disposición a reflexionar» (JASPERS, 1998).

Aunque Francisco LAPORTA no lo expresa así, creo que podemos interpretar esa disposición a reflexionar como el primer paso en la asunción de una responsabilidad colectiva ante el Holocausto para restañar la herida civilizatoria, un hacernos cargo vicariamente de lo ocurrido. Sería una responsabilidad que iría tanto al pasado, reflejada en la obligación de reparar, a nuestro presente - concretada en la obligación de recordar y también hacia el futuro, plasmada en la obligación de impedir-. Estas tres obligaciones serían el resultado de nuestra responsabilidad colectiva vicaria en el mantenimiento mismo de nuestro universo moral frente a la barbarie. Las tres obliga-

7 Los análisis sobre la participación de la población alemana en el exterminio de los judíos son muy numerosos. Baste citar como muestra, además de la conocida —y polémica - obra de D. GOLDHAGEN, Los verdugos voluntarios de Hitler. Los alemanes corrientes y el Holocausto, Madrid, Taurus, 1997; las de R. GELLATELLY, No solo Hitler. Consentimiento y represión en la Alemania nazi, Barcelona, Crítica, 2002; E. JoHnson, El terror nazi: La Gestapo, los judios y el pueblo alemán, Barcelona, Paidós, 2002 y P. FRITZsCHE, De alemanes a nazis, 1914-1933, Buenos Aires, Siglo XXI, 2006. 
ciones son —y siguen siendo—objeto de numerosos debates: ¿Es el recuerdo un deber moral? Y si lo es ¿Para quién es esa obligación? Las políticas públicas de la memoria juegan sin duda aquí un papel central, con todas las dificultades que se plantean en la elaboración y gestión de una memoria pública tras la violencia. Las reparaciones, como han puesto de manifiesto los procesos de justicia transicional, se enfrentan también a serias complicaciones: ¿Son reparaciones colectivas o individuales? Qué papel juega lo simbólico en ellas? ¿Y el perdón? Por último, la obligación de impedir o evitar debería ser capaz de detectar — más allá de supuestos determinismos históricos- los peligros, los elementos pretotalitarios que pueden estar larvados en nuestras sociedades. «Todo depende de nosotros», como afirma LAPORTA (2016). Una sociedad civil robusta, el debate público abierto y el reconocimiento institucional de la igual dignidad de todos los seres humanos deberían ser parte ineludible de esa obligación de impedir.

\section{BIBLIOGRAFÍA}

ARENDT, H., 2007: «Responsabilidad colectiva», en Responsabilidad y juicio, Barcelona: Paidós. ARTETA, A., 2010: Mal consentido. La complicidad del espectador indiferente, Madrid: Alianza Editorial.

FeInBERG, J., 1968: «Collective Responsibility», Journal of Philosophy, 65.

GARZÓN VALDÉs, E., 2011a: «El enunciado de responsabilidad», en Propuestas, Madrid: Trotta.

- 2011b: «Respuesta a la violencia extraordinaria», en Propuestas, Madrid: Trotta.

HeLD, V., 1991: «Can a Collection of Individuals be Morally Responsible?», en L. MAY y S. Hoffman (eds.), Collective Responsibility. Five Decades of Debate in Theorethical and Applied Ethics, Oxford: Rowman and Littlefield.

JASPERS, K., 1998: El problema de la culpa, Madrid: Alianza Editorial. MAY, L., 1992: Sharing Responsibility, Chicago, Chicago University Press.

Mellema, G., 1997: Collective Responsibility, Amsterdam: Rodopi Press.

Young, I. M., 2011: Responsibility for Justice, Oxford, Oxford University Press. 